\title{
Pandemia, Direito e Solidariedade: O Que Diria Calmon?
}

\author{
Pandemia, Law and Solidarity: What Would Calmon Say?
}

Marcus Seixas Souza'

${ }^{1}$ Faculdade Baiana de Direito, Brasil

\section{Resumo}

O presente ensaio analisa um capítulo específico da obra "Direito, Poder, Justiça e Processo: Julgando os que nos Julgam”, de José Joaquim Calmon de Passos, intitulado “A Produção do Direito sob a Ótica do Dever”, e procura relacionar algumas das ideias do autor com o momento atual de crise social decorrente da pandemia de COVID-19.

Palavras-chave: Calmon de Passos; Pandemia; Solidariedade.

\begin{abstract}
This essay analyzes a specific chapter of the work "Direito, Poder, Justiça e Processo: Julgando os que nos Julgam”, by José Joaquim Calmon de Passos, entitled "A Produção do Direito sob a Ótica do Dever", and seeks to connect some of the author's ideas with the current moment of social crisis resulting from the COVID-19 pandemic.
\end{abstract}

Keywords: Calmon de Passos; Pandemics; solidarity.

\section{A obra jurídica}

O presente ensaio analisa um capítulo específico da obra "Direito, Poder, Justiça e Processo: Julgando os que nos Julgam”, de José Joaquim Calmon de Passos, intitulado "A Produção do Direito sob a Ótica do Dever", e procura relacionar algumas das ideias do autor com o momento atual de crise social decorrente da pandemia de COVID-19.

No referido capítulo, Calmon dirige a sua reflexão à conexão entre a liberdade, o direito e o dever - buscando demonstrar que no albor da modernidade justificou-se a ênfase dada ao sujeito, sua autonomia e liberdade, consequentemente a seus direitos; e que ao tempo em que escrevia já se impunha um retorno ao dever como estrutura central da normatividade, ferramenta de auto-limitação da liberdade a fim de engendrar solidariedade social e segurança para a convivência humana.

\footnotetext{
1 PASSOS, J. J. Calmon de. Direito, Poder, Justiça e Processo: Julgando os que nos Julgam. Rio de Janeiro: Forense, 2000.
} 


\section{Direito e poder}

Calmon principia as suas considerações retomando um assunto já explorando em outras passagens ${ }^{2}$ do livro acima referido: a premissa segundo a qual a produção do Direito é sempre reservada a quem monopoliza o uso legítimo da força.

Apesar da associação entre Direito e poder, Calmon não acreditava na construção totalmente arbitrária do Direito por parte dos detentores do poder. Em sua visão, os "dominados" também podem exercer uma "parcela de contra-poder" - atuando, portanto, como partícipes no processo de criação do Direito na medida em que colaboram na limitação ao poder exercido pelos "dominadores". ${ }^{3}$

Argumentou Calmon que o poder político jamais pôde ser exercido de forma duradoura sem se legitimar ideologicamente em face dos governados: é a adesão destes que viabiliza a eficácia e efetividade dos sistemas de dominação institucionalizado. Em razão disso:

Todo sistema político-econômico-jurídico nutre-se, portanto, da ideologia que elabora e consegue introjetar, com êxito, no imaginário coletivo. E dura enquanto consegue. De quanto dito, resulta claro que a produção do Direito, antes de ser uma tarefa de técnicos, e um produto da política. ${ }^{4}$

Sob esse prisma é que se compreende a visão de Calmon segundo a qual o processo de produção do Direito depende da realidade social que busca ordenar e a ela funcionalmente se vincula. Mediante a institucionalização de modelos ou esquemas de solução de conflitos coercitivamente aplicáveis aos casos concretos, o Direito é instrumento que proporciona segurança jurídica ao sistema de dominação política.

\section{Sobre a desigualdade}

Às considerações acima se relaciona a percepção de Calmon a respeito da desigualdade entre os homens. Para Calmon, é da essência do Direito relacionar as pessoas desigualando-as: "sem que se entenda haver algo devido necessariamente por alguém em proveito de outrem, que a isso faz jus, é impensável o Direito e desnecessário”.

Nessa linha, o Direito existiria justamente para tutelar as situações em que os sujeitos envolvidos em um conflito não são capazes de chegar por outros meios a um consenso sobre o que deve ser atribuído a alguém por justiça.

Para determinar o justo nas relações de conflito é que existiria a política. A determinação do justo seria ato político, ato de poder e de criação do Direito. Quando o Direito estabelece que algo devido por alguém em face de outrem, criar-se-ia, por si só, uma desigualdade fruto da resolução heterônoma (e jurídica) do conflito.

Para Calmon, os homens seriam, naturalmente desiguais. Tratar-se-ia, em sua visão, de um dado da natureza: os homens possuiriam diferentes potencialidades e características, o que produziria, inevitavelmente, diferenças e desigualdades que se verificariam no plano dos fatos.

Os direitos, portanto, também traduziriam um exercício de poder de um sujeito em face de outro. Mesmo quando o Direito procura compensar desvantagens sociais ou pessoais, exerceria coerção externa sobre aquele que possui as referidas vantagens, e que eventualmente se vê impossibilitado de exercer todas as suas potencialidades ou poderes de fato em face de outrem. Em outras palavras, nesses casos se impõe uma nova relação de dominação, ainda que heterônoma. ${ }^{5}$

2 Especialmente no capítulo intitulado "Direito e Poder: A Dimensão Política do Jurídico" (PASSOS, J. J. Calmon de. Direito, Poder, Justiça e Processo: Julgando os que nos Julgam, cit., p. 41-52).

3 PASSOS, J. J. Calmon de. Direito, Poder, Justiça e Processo: Julgando os que nos Julgam, cit., p. 93.

4 PASSOS, J. J. Calmon de. Direito, Poder, Justiça e Processo:Julgando os que nos Julgam, cit., p. 94.

5 PASSOS, J. J. Calmon de. Direito, Poder, Justiça e Processo: Julgando os que nos Julgam, cit., p. 96. 
No esforço por transcender a animalidade, os seres humanos teriam lutado para reconhecer a dignidade pessoal e a igualdade social, antinatural e construída artificialmente pela Modernidade. ${ }^{6}$

Para o alcance da igualdade social almejada, se fez necessária a noção de "dever", da qual se infere, por contraposição, a noção de "direito". Para Calmon, o direito, enquanto associado a poder, é co-natural ao animal-homem, no sentido de que lhe estaria assegurada, por natureza, "a utilização de seu diferencial até ao limite de sua conveniência, necessidade e possibilidade". Desta forma, foi a noção de "dever" que precisou ser construída de forma antinatural: a ideia de que aquele que detém um diferencial que o beneficia em face de outrem não possa utilizá-lo sem considerar também o interesse e a necessidade daquele com quem interage e se relaciona em situação de inferioridade. ${ }^{7}$

"Para se ter direito, basta a força; para se ter dever, a ética seria imprescindível". ${ }^{8}$ Dissociar-se o direito do mero exercício da força de que se dispõe só é possível se se pensar o direito em função do dever, entendido enquanto limite imposto ao direito "natural" de se exercer o diferencial de poder de que dispõe. Esta, para Calmon, seria uma reflexão perdida em nosso tempo e que precisa ser recuperada, ${ }^{9}$ de forma a alicerçar a harmonia social e a democratização do poder. ${ }^{10}$

\section{O resgate do dever}

Assim é que Calmon, observando historicamente a tessitura normativa dos Direitos préModernos (na Antiguidade e na Idade Média) percebeu que tais sistema jurídicos estavam fundados na ideia de dever, embora essa normatividade quase sempre se legitimasse em uma fonte material externa (a religião, a tradição, a natureza das coisas etc.): em vez de se enfatizar o direito à vida, se afirmava o dever de não matar; em vez de se realçar o direito à propriedade, estabelecia-se um dever de não cobiçar as coisas alheias e de não as furtar. ${ }^{11}$

Foi a Modernidade tornou o homem medida de si mesmo, portador de uma "dignidade" tal que o legitimaria a pretender algo em face de seu semelhante, e assim moldou a figura do sujeito de direitos, titular de direitos subjetivos, direitos individuais. O subjetivismo e o individualismo enfatizaram a liberdade e a autonomia, e os “direitos" em detrimento dos “deveres”. O indivíduo passou a ser uma instância soberana, e seus direitos, expressão dessa soberania.

Com essas palavras Calmon não quis diminuir a importância das declarações de direitos ou dos direitos fundamentais, mas apenas enfatizar que a sua positivação é falaciosa quando desassistida de vontade pessoal, social e política que efetivamente as institucionalize - vontade esta que não decorre de mera imposição normativa.

Nas palavras de Calmon:

Consequência necessária desta radical mudança de paradigma foi a hipertrofia do sujeito e de sua afirmação, do reconhecimento do direito de plena realização pessoal do indivíduo e de objetivar e otimizar todas as suas potencialidades, o que implica a ênfase na liberdade em detrimento da responsabilidade e da competição em desfavor da solidariedade..$^{12}$

Essas transformações teriam produzido, para o autor, uma progressiva conflitualidade na convivência social, fomentando nos indivíduos a perda da referência do outro, "somente recuperável com a introjeção do dever como valor". ${ }^{13}$ Só enfatizando o dever colocamos o outro na esfera de nossa responsabilidade e mobilizamo-nos para a solidariedade.

6 PASSOS, J. J. Calmon de. Direito, Poder, Justiça e Processo: Julgando os que nos Julgam, cit., p. 95.

7 PASSOS, J. J. Calmon de. Direito, Poder, Justiça e Processo: Julgando os que nos Julgam, cit., p. 95.

8 PASSOS, J. J. Calmon de. Direito, Poder, Justiça e Processo: Julgando os que nos Julgam, cit., p. 95.

9 PASSOS, J. J. Calmon de. Direito, Poder, Justiça e Processo: Julgando os que nos Julgam, cit., p. 95.

10 PASSOS, J. J. Calmon de. Direito, Poder, Justiça e Processo: Julgando os que nos Julgam, cit., p. 96.

11 PASSOS, J. J. Calmon de. Direito, Poder, Justiça e Processo:Julgando os que nos Julgam, cit., p. 96-98.

12 PASSOS, J. J. Calmon de. Direito, Poder, Justiça e Processo: Julgando os que nos Julgam, cit., p. 98.

13 PASSOS, J. J. Calmon de. Direito, Poder, Justiça e Processo: Julgando os que nos Julgam, cit., p. 99. 
Enfatizar os direitos, inversamente, só ajuda a criar uma contraposição em face do outro, na medida em que traz para o primeiro plano uma relação entre adversário e oponente, ou, como afirmado anteriormente, uma relação de poder. ${ }^{14}$

\section{Sobre o futuro}

Tendo consciência do comportamento disfuncional da sociedade e do sistema jurídico, Calmon anteviu dois desfechos diferentes para a história do homem moderno.

Na Introdução à sua obra, Calmon já anunciara que construíra uma convicção robusta de que o futuro tenderia para uma destas alternativas (com as muitas variáveis que comportam): ou seríamos incapazes de minimizar os efeitos destrutivos do sistema capitalista, o que determinará desagregação e ruptura, ou lograremos recuperar poder político para a sociedade (o espaço do homem comum) com o que se fará possível fixar limites e impor diretivas ao processo econômico e às atividades de governo, colocando-as a serviço dos homens e não obcessivamente voltadas para o lucro, a produtividade e a eficiência. ${ }^{15}$

Na parte final do capítulo sobre "A Produção do Direito sob a Ótica do Dever", Calmon retomou o assunto, propondo dois cenários muito diferentes um do outro.

O primeiro deles, pessimista e trágico, decorreria da continuidade do status quo, e a potencialização de uma sociedade em que a solidariedade não se apresenta como um valor relevante. Nesse primeiro cenário, poder-se-ia aludir à irônica e trágica alegoria de autoria de Robert Kurz, o espetáculo do "último capitalista do mundo (imagem substituível pela do último poderoso - chefão, ou do último titular de direitos fundamentais) na varanda de sua rica mansão, protegido por uma máscara contra a poluição atmosférica, bebendo o último gole de água potável existente na Terra”. ${ }^{16}$

Outra possibilidade, menos trágica, seria um compromisso social de deslocamento da ênfase para o dever, buscando na descoberta da dignidade do semelhante a reavaliação e o reconhecimento de nossa própria dignidade. ${ }^{17}$

\section{Pandemia e solidariedade social}

Em meio à pandemia de COVID-19 experimentada hoje, quando a solidariedade social se faz mais importante do que nunca, seria o caso de tentar identificar a existência de passos dados pela sociedade em direção a um ou outro cenário, entre os dois antecipados por Calmon.

Lamentavelmente, a pandemia ressaltou a desigualdade social e a luta de classes; o isolamento do indivíduo em face da coletividade e a ausência de solidariedade social.

Sabe-se que muitos brasileiros conscientemente ignoram os fatos científicos sobre a pandemia de COVID-19 e não utilizam máscaras, não adotam hábitos de higiene, fazem reuniões e aglomerações, inclusive festas; e ajudam a espalhar o vírus e potencializar os seus efeitos danosos na sociedade.

É incontroverso que determinados governos minimizam os efeitos da pandemia ou a necessidade de adoção de medidas de controle da dispersão da doença para minimizar os efeitos erosivos desta sobre os números do desempenho econômico destes governos.

Não há dúvidas de que os trabalhadores do setor de saúde estão expostos a altos riscos no combate à doença em razão de não lhes serem disponibilizados EPIs em quantidade e qualidade adequadas, a despeito de estarem na linha de frente do combate à doença.

14 PASSOS, J. J. Calmon de. Direito, Poder, Justiça e Processo: Julgando os que nos Julgam, cit., p. 102.

15 PASSOS, J. J. Calmon de. Direito, Poder, Justiça e Processo: Julgando os que nos Julgam, cit., p. 1.

16 PASSOS, J. J. Calmon de. Direito, Poder, Justiça e Processo: Julgando os que nos Julgam, cit., p. 99.

17 PASSOS, J. J. Calmon de. Direito, Poder, Justiça e Processo:Julgando os que nos Julgam, cit., p. 99-100. 
Todos os dias, os "motoristas de aplicativos" se expõem a altos riscos para sobreviver nas atuais circunstâncias, e sua atividade é considerada essencial por muitos; mas, ainda assim, não lhes são assegurados direitos necessários para que estejam amparados socialmente, inclusive na hipótese de adoecerem em razão do COVID-19. A manutenção das condições de subemprego desses trabalhadores é conveniente para as empresas que exploram seu trabalho e para uma classe média cada vez mais acostumada a se utilizar de seus serviços.

Enquanto a iniciativa privada foi amplamente impactada pelos efeitos econômicos da pandemia (na medida em que foram adotadas reduções de jornada, suspensão dos contratos de trabalho, demissões, interdição de determinadas atividades econômicas, e empresas pleitearam recuperação judicial ou falência etc.) o funcionalismo público se blindou contra os efeitos econômicos da crise.

Se tornou pública a informação de que uma grande quantidade de brasileiros pediu e recebeu o auxílio emergencial do governo federal destinado às pessoas economicamente vulneráveis no período da pandemia, ainda que não tivessem direito ao mesmo, valendo-se do fato de que o filtro utilizado pelo governo para determinar quem poderia ou não receber o mencionado auxílio era ineficiente.

Esses relatos acima indicados parecem provar a falta de coesão e solidariedade social mesmo em um dos momentos mais desafiadores para as sociedades. Protegidos por seus direitos, os indivíduos parecem não sentir a necessidade de se solidarizar com o outro, como se não existissem deveres que lhes vinculassem e imputassem um agir em prol de interesses que não os seus pessoais.

Um tal cenário jamais inspirará a solidariedade e a obtenção de condições dignas de vida para todos os cidadãos que convivem em sociedade. Só o fim do solipsismo e a assunção de um dever para com o outro e para com a sociedade como um todo poderá viabilizar a dignidade dos cidadãos que convivem em sociedade.

Afinal, como afirmou Calmon, "pouco importam os mandamentos dos deuses para os que não tem fé, bem como de nada valem as proclamações de direitos para os que não têm consciência do dever". ${ }^{18}$

\section{Referências}

PASSOS, J. J. Calmon de. Direito, Poder, Justiça e Processo: Julgando os que nos Julgam. Rio de Janeiro: Forense, 2000. 